Original Article

\title{
DEVELOPMENT OF MUCOADHESIVE TABLET OF PENTOXIFYLLINE USING A NATURAL POLYMER FROM MANILKARA ZAPOTA LINN
}

\author{
GNANASEKARAN JOHN SELVARAJ, ARUL BALASUBRAMANIAN*, KOTHAI RAMALINGAM
}

Vinayaka Mission's College of Pharmacy, Vinayaka Mission's Research Foundation (Deemed to be University) Salem 636008, Tamilnadu, India Email: arul1971@yahoo.com

Received: 26 Jan 2019, Revised and Accepted: 17 Apr 2019

\section{ABSTRACT}

Objective: The present study was designed to develop a mucoadhesive tablet of pentoxifylline using the mucoadhesive natural polymer from the plant Manilkara zapota Linn.

Methods: The tablets were formulated with three different concentrations of the isolated polymer and evaluated for thickness, weight variation, friability, hardness, swelling index, mucoadhesive strength and in vitro drug release. The swelling index was indirectly proportional to the mucoadhesive polymer of Manilkara zapota (MAPMZ) concentration.

Results: The tablets formulated with a high concentration of MAPMZ showed good mucoadhesion strength in 5 min contact time. The in vitro drug release studies indicated that the drug release was directly proportional to MAPMZ concentration. The release kinetics indicated that the drug release was followed the zero-order.

Conclusion: The MAPMZ showed the controlled release of pentoxifylline for a period of $12 \mathrm{~h}$.

Keywords: Mucoadhesion, Pentoxifylline, Manilkara zapota

(C) 2019 The Authors. Published by Innovare Academic Sciences Pvt Ltd. This is an open-access article under the CC BY license (http://creativecommons.org/licenses/by/4.0/) DOI: http://dx.doi.org/10.22159/ijap.2019v11i4.32177

\section{INTRODUCTION}

Mucoadhesive drug delivery system has recently gained more interest in pharma profession [1]. Mucoadhesion is a facet of bioadhesion that is aimed to localize the drugs at a certain mucosal area in the body. Watersoluble polymers, those become adhesive on hydration, has been used to design the formulation. The most important aims of mucoadhesion are drug targeting, sustained/controlled release, increasing of gastric residence time, minimizing the first pass effect and reducing the adverse effects [2, 3]. The polymers chosen for mucoadhesion must be nonabsorbable, non-toxic, biocompatible, non-covalent adhesive and economic [4]. These polymers may be either natural (sodium alginate, gelatin and guar gum) or synthetic/semi-synthetic (sodium carboxymethyl cellulose, carbopol 934 and hydroxypropyl methylcellulose) [5-9]. They may be used either alone or blends of two or more adhesive polymers for mucoadhesive systems.

Manilkara zapota Linn. (M. zapota), is an evergreen plant belongs to the family Sapotaceae, grows up to 8-15 m height. It is cultivated throughout Indian subcontinent including Bangladesh, though it is native to Mexico and Central America. The seeds of M. zapota are diuretic tonic aperients and febrifuge. Stem bark is act as an astringent, febrifuge [10] and anticancer [11]. The leaves and bark are used to treat cough, cold, dysentery and diarrhea [12]. Antimicrobial and antioxidant activities are also reported from the leaves of $M$. zapota $[13,14]$. A natural gum from the seeds of the plant was also isolated [15].

Even though many advances have been made in the area of mucoadhesives, still many challenges ahead in this area and also the search for newer mucoadhesives are going on. The objective of this study was to develop mucoadhesive tablets of pentoxifylline using the mucoadhesive polymer from the plant Manilkara Zapota Linn. (MAPMZ) with respect to the in vitro drug release rate and the characterization of the isolated polymer.

\section{MATERIALS AND METHODS}

\section{Materials}

The seeds of Manilkara zapota were purchased from the local vendors of Chennai, Tamilnadu in the month of December 2017. The collected seeds were identified and authenticated by a botanist Dr. S. Balasubramanian, ABS Medicinal garden, Salem. The voucher specimen (MZG-1) was kept in our museum for future reference. Pentoxifylline was obtained as a gift sample from Shasun Pharmaceuticals, Puducherry. Avicel and magnesium stearate were purchased from Central Drug House (India). Acetone, diethyl ether and petroleum ether were from Qualigens (India) and sodium hydroxide from E-Merck (India). All the chemicals used were of analytical grade

\section{Methods}

\section{Isolation of MAPMZ}

Three batches of MAPMZ was prepared on a laboratory scale by the method of Rao et al. [16]. $200 \mathrm{ml}$ of cold distilled water was added to 20 $\mathrm{g}$ of the seed powder and the slurry was prepared. Then the slurry was added to $800 \mathrm{ml}$ of boiling water and boiled for another $20 \mathrm{~min}$ with continuous stirring. The solution was kept overnight to settle the solid matter. The clear solution was centrifuged for $20 \mathrm{~min}$ at $5000 \mathrm{rpm}$. The supernatant fluid was separated and twice the volume of acetone was added with continuous stirring. The formed precipitates were filtered and washed with petroleum ether and diethyl ether and then dried under vacuum at $50-60{ }^{\circ} \mathrm{C}$. The dried materials were sieved through sieve No 80 and used for the formulation of tablets.

\section{Formulation of mucoadhesive tablets}

The mucoadhesive tablets (MAT) of pentoxifylline were prepared by using direct compression technique. Accurately weighed quantities of pentoxifylline, mucoadhesive polymer, avicel, magnesium stearate were mixed uniformly and this mixture was compressed into tablets by using Elite multi-station punching machine (Erweka) with $10 \mathrm{~mm}$ flat punches. The compression force was adjusted to give tablet hardness in the range of 7 to $11 \mathrm{kp}$. The constituent of the formulation is presented in table 1.

\section{Swelling study}

The formulated MAT's were individually weighed (W1) and placed separately in an agar gel $(2 \%)$ plates and incubated at $37 \pm 0.5^{\circ} \mathrm{C}$. The tablets were removed from petri dish at regular time intervals of $1 \mathrm{~h}$ up to $6 \mathrm{~h}$ and the excess water on the surface was removed carefully with filter paper. The swollen tablet was reweighed (W2) and the swelling index was calculated $(n=3)$ by using the formula $[17,18]$.

$$
\text { Swelling index }=\frac{\mathrm{W} 2-\mathrm{W} 1}{\mathrm{~W} 1}
$$


Table 1: Formulation of mucoadhesive tablets of pentoxifylline

\begin{tabular}{|c|c|c|c|}
\hline Ingredients & F1 & F2 & F3 \\
\hline Pentoxifylline & 400 & 400 & 400 \\
\hline Avicel & 152 & 122 & 92 \\
\hline MAPMZ & 30 & 60 & 90 \\
\hline Magnesium stearate & 18 & 18 & 18 \\
\hline Total weight (mg) & 600 & 600 & 600 \\
\hline
\end{tabular}

All the quantities are in $\mathrm{mg}$

\section{Mucoadhesive strength}

The mucoadhesive strength (MS) of the formulated MAT's was measured by using a modified 2-arm balance (fig. 1) with rabbit buccal mucosa[19]. The rabbit buccal mucosa was taken as the membrane and phosphate buffer (PB) pH 6.8 as moisturizing liquid. The rabbit buccal mucosa was obtained from the local slaughterhouse and stored in krebs buffer at $4{ }^{\circ} \mathrm{C}$ upon collection. The experiment was conducted within $3 \mathrm{~h}$ of the procurement of rabbit mucosa. The mucous layer was separated by using a surgical blade and washed with PB pH 6.8. It was then tied on a glass vial using a thread. This set was kept in a glass beaker, which was filled with PB pH 6.8 up to the surface of the buccal mucosa to maintain buccal mucosa viability.

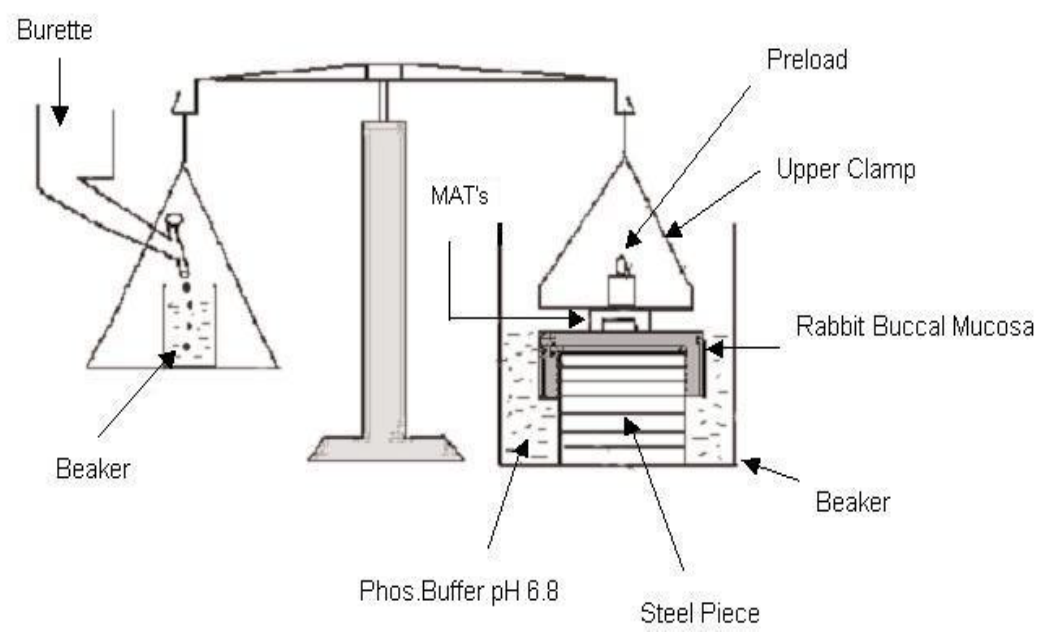

Fig. 1: Mucoadhesive strength measurement apparatus [19]

The MAT was attached to the upper clamp of the apparatus and then the beaker was raised slowly until contact between rabbit buccal mucosa and MAT was established. A weight of $100 \mathrm{~g}$ was kept on the clamp for $5 \mathrm{~min}$ (pre-load time) to create a strong adhesion between rabbit buccal mucosa and the MAT. The weight $(100 \mathrm{~g})$ and pre-load time (5 min) were kept as constant for all the MAT's. After the preload time, the weight was removed from the clamp. Water was added at a rate of 60 drops/min into the beaker until the separation of rabbit buccal mucosa and MAT. The weight of water required to detach the MAT from buccal mucosa was noted as MS and the same was repeated with fresh mucosa $(n=6)$. The force of adhesion [2022] was calculated by using MS

$$
\text { Force of adhesion }(\mathrm{N})=\frac{\mathrm{MS}}{100} \times 9.81
$$

\section{In vitro drug release studies}

The in vitro dissolution studies were carried out in a USP dissolution test apparatus (Electrolab, India) Type-II, by using $900 \mathrm{ml}$ of phosphate buffer saline (PBS) $\mathrm{pH}$ 6.8. The dissolution test was carried out at a speed of $50 \mathrm{rpm}$ and the temperature of $37 \pm 0.5^{\circ} \mathrm{C} .5$ $\mathrm{ml}$ of the samples were withdrawn at predetermined time intervals and assayed spectrophotometrically at $274 \mathrm{~nm}$ using Shimadzu UV spectrophotometer 1601. All the experiments were done thrice $(\mathrm{n}=3)$ and the standard curve specification was $\mathrm{y}=0.0392 \mathrm{X}\left(\mathrm{r}^{2}=\right.$ 0.9993, $\mathrm{n}=10$ ).

\section{Drug release kinetics}

The data obtained from in vitro release of drug was plotted in various kinetic models such as zero order (cumulative amount of drug released vs time), first order (log cumulative percentage of drug remaining vs time), and Higuchi's model (cumulative percentage of drug released vs square root of time) to know the release kinetics [23-25].

\section{Mechanism of drug release}

The mechanism of drug release of the prepared mucoadhesive tablet of pentoxifylline was calculated by using Korsmeyer equation (log cumulative percentage of drug released vs log time), and the exponent $\mathrm{n}$ was calculated through the slope of the straight line [26].

\section{Statistical analysis}

Each experiment was repeated at least three times. The results are expressed as the mean \pm SD One-way analysis of variance was used to test the statistical significance of differences among groups. Statistical significance of the differences of the means was determined by Student's t-test.

\section{RESULTS AND DISCUSSION}

Natural polymers are preferred over synthetic and semi-synthetic polymers due to their low cost, non-toxic, emollient, free availability and non-irritating nature. Even though many polymers are available, a search for new polymers still interesting to get more efficacious polymers with less toxic. So in this present work, an attempt was made to study the mucoadhesive property of the natural polymer from the plant $M$. zapota by formulating pentoxifylline mucoadhesive tablets.

The mucilage was isolated from the seeds of M. zapota by the method of Rao et al., [16]. The mucoadhesive tablets of pentoxifylline were formulated by using three different concentrations of MAPMZ. 
The evaluation of tablets showed a satisfactory report on hardness $(92.572 \pm 3.641$ Neutons), friability $(0.325 \pm 0.005 \%)$, weight variation $(0.6106 \mathrm{mg} \pm 3.24 \%)$ and drug content $(101.97 \pm 1.62 \%)$.

An appropriate swelling index is mandatory for the uniform and sustained release of the drug and effective mucoadhesion [27]. The swelling study showed that the rate of swelling was indirectly proportional to the MAPMZ content of tablets. F1 batch (lower concentration of MAPMZ) had a high swelling index (4.292 \pm 0.10$)$, and F3 the lowest $(3.10 \pm 0.07)$ swelling index. Batch F2 and F3 didn't show any significant change in their shape and form of tablets for a period of $6 \mathrm{~h}$, when they kept in the agar gel (2\%) plate. But the F1 batch had completely changed the shape and form.
MS of MAT's of Manilkara zapota with rabbit buccal mucosa is shown in fig. 2. The mucoadhesion was occurred in three different stages: wetting, interpenetration, and mechanical interlocking between mucus and polymer. The MS is affected by various factors such as polymer's molecular weight [28], swelling rate, contact time with mucus, and the biological membrane used for the study [29]. Tablets formulated with a high concentration of MAPMZ showed good MS in a contact time of $5 \mathrm{~min}$. This high mucoadhesive strength of MAPMZ may be due to the formation of secondary bioadhesion bonds with mucin and interpenetration of the polymer chains in the interfacial region. However, the formulations F1, F2 and F3 exhibited MS of $10.302 \pm 0.241,33.752 \pm 0.246$ and $36.762 \pm 0.134 \mathrm{gm}$, respectively, with rabbit buccal mucosa.

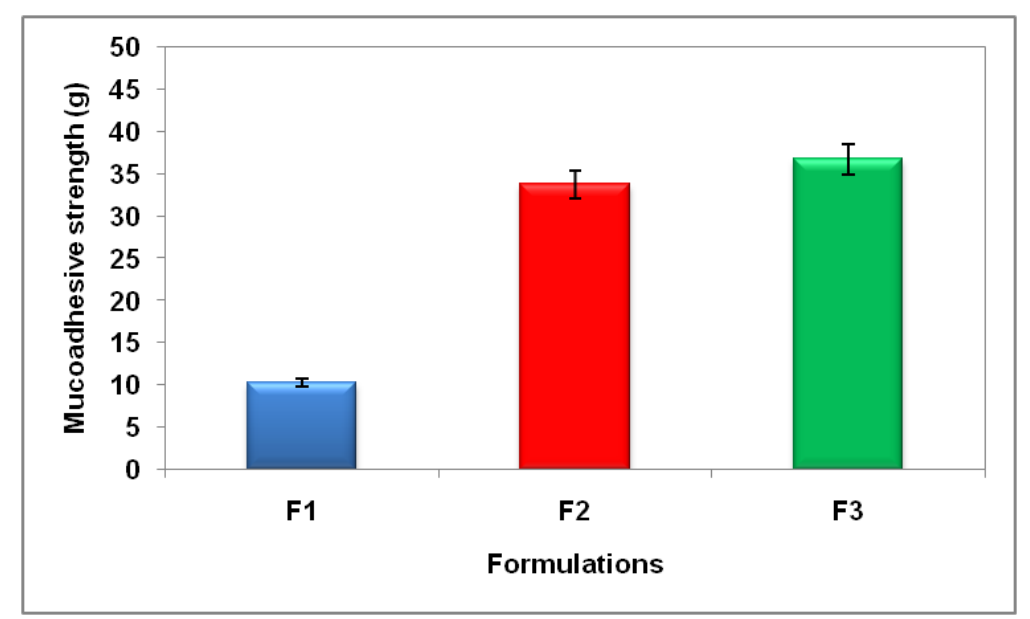

Fig. 2: Mucoadhesive strength of tablets formulated with $M A P M Z$ mean $\pm S D, n=6$

The in vitro release studies (fig. 3 ) revealed that the release rate was indirectly proportional to the MAPMZ concentration. The F1 batch, which has a high swelling index, leads to more \% of drug diffused from the polymer matrix [30]. The gradual decrease in the $\%$ of drug release from $\mathrm{F} 1(98.05 \pm 2.51)$ to $\mathrm{F} 3(60.16 \pm 2.64)$, in $5 \mathrm{~h}$, may be due to the increase in the concentration of MAPMZ. It may be due to the in situ gelling property of MAP, which slows the dissolution rate of the drug pentoxifylline. Tablets of batch F2 and F3 were remaining intact during the entire $12 \mathrm{~h}$ study period and the batch F1 was up to $5 \mathrm{~h}$.

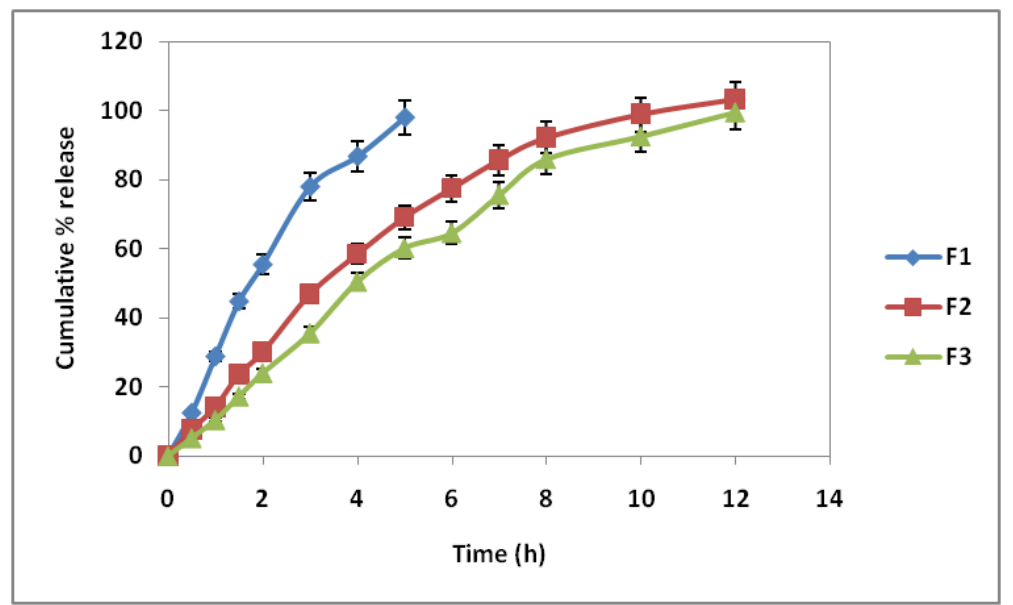

Fig. 3: The cumulative release profile of mucoadhesive tablets of pentoxifylline formulated with MAPMZ mean $\pm S D, n=3$

The zero order release described that the release rate is doseindependent, which shows the cumulative amount of drug release vs time for zero-order kinetics. The first order release described the release rate is dose-dependent, which shows the log cumulative percent drug remaining vs time [31]. Higuchi's model described the release of drugs from an insoluble matrix as a square root of a timedependent process based on Fickian diffusion. Higuchi square root kinetics, showing the cumulative percent drug release vs the square root of time[32]. The release constant was calculated from the slope of the appropriate plots, and the regression coefficient $\left(\mathrm{r}^{2}\right)$ was determined (table 2). It was found that the in vitro drug release of mucoadhesive tablets of pentoxifylline was followed zero order release, as the plot showed the highest linearity $\left(\mathrm{r}^{2}=0.9552,0.9262\right.$ and 0.9585 for the formulations, F1, F2 and F3 respectively), and Higuchi's ( $\mathrm{r}^{2}=0.9916,0.9845$ and 0.99$)$, which indicates the release rate independent. 
Table 2: Release kinetics of mucoadhesive tablets of pentoxifylline

\begin{tabular}{|c|c|c|c|c|c|c|c|c|}
\hline \multirow[t]{2}{*}{ Formulation } & \multicolumn{2}{|c|}{ First order } & \multicolumn{2}{|c|}{ Zero-order } & \multicolumn{2}{|l|}{ Higuchi } & \multicolumn{2}{|c|}{ Korsmeyer Peppas } \\
\hline & Slope & $r^{2}$ & Slope & $r^{2}$ & Slope & $r^{2}$ & Slope & $r^{2}$ \\
\hline F1 & 0.3357 & 0.9186 & 19.891 & 0.9552 & 57.128 & 0.9916 & 0.8854 & 0.9716 \\
\hline $\mathrm{F} 2$ & 0.1675 & 0.9205 & 9.2043 & 0.9262 & 38.352 & 0.9845 & 0.9163 & 0.9920 \\
\hline F3 & 0.1594 & 0.8538 & 8.9379 & 0.9585 & 37.419 & 0.99 & 0.9887 & 0.991 \\
\hline
\end{tabular}

The corresponding Korsmeyer-Peppas [30] plot (log cumulative percent drug release vs time) indicated good linearity ( $\mathrm{r}^{2}=0.9716$, 0.992 and 0.991) and showed the matrix release pentoxifylline.

\section{CONCLUSION}

Reducing the frequency of the administration of the drug pentoxifylline will increase patient compliance and also reducing the dose-related side effects. The MAT's formulated with MAPMZ controlled the release of pentoxifylline for $12 \mathrm{~h}$; hence, the formulation may be considered as a once-daily sustained-release tablet of pentoxifylline. The in vitro dissolution studies indicated a sustained-release pattern of the drug pentoxifylline for $12 \mathrm{~h}$ of study. The results of this study revealed that increasing the concentration of the polymer leads to a decrease in the release rate and also increases the adhesion strength of the formulation. Drug release kinetics indicated that drug release was followed zero-order equation, as the plot showed the highest linearity.

\section{AUTHORS CONTRIBUTIONS}

All authors have contributed equally

\section{CONFLICTS OF INTERESTS}

All authors have none to declare

\section{REFERENCES}

1. Jimenez Castellanos NR, Zia H, Rhodes CT. Mucoadhesive drug delivery systems. Drug Dev Ind Pharm 1993;19:143-94.

2. Ahuja A, Khar RK, Ali J. Mucoadhesive drug delivery systems. Drug Dev Ind Pharm 1997;23:489-515.

3. Nagai T, Machida Y. Advances in drug delivery, mucosal adhesive dosage forms. Pharm Int 1985;6:196-200.

4. Gayot A. Bioadhesive polymers. J Pharm Belg 1985;40:332-8.

5. Sang Chl S, Ja Young K. Enhanced permeation of triamcinolone acetonide through the buccal mucosa. Eur J Pharm Biopharm 2000;40:217-20.

6. Cilurzo F, Minghetti P, Selmin F, Casiraghi A, Montanari L. Polymethacrylate salts as new low-swellable mucoadhesive material. J Controlled Release 2003;88:43-53.

7. Han Gon C, Jac Hee J, Chul Soon Y, Chong Dal R, Mi Kyung L, Jeong Hee $\mathrm{H}$, et al. Formulation and in vitro evaluation of omeprazole buccal adhesive tablet. J Controlled Release 2000;68:405-12.

8. Miyazaki S, Kawasaki N, Nakamura T, Iwatsu M, Hayashi T, Hou $\mathrm{WM}$, et al. Oral mucosal bioadhesive tablets of pectin and HPMC: in vitro and in vivo evaluation. Int J Pharm 2000;204:127-32.

9. Shah HP, Prajapati ST, Patel C. Gastroretentive drug delivery systems: from conception to commercial success. J Crit Rev 2017;4:10-21.

10. Patricia LDM, Maria RAM, Luis COL, Jose DA, Ricardo EA, Jose DS. Cell wall biochemistry of sapodilla (Manilkara zapota) submitted to 1-methylcyclopropene. Braz J Plant Physiol 2008;20:85-94.

11. Abu Osman M, Mamunur Rashid M, Abdul Aziz M, Rowshahul Habib M, Rezaul Karim M. Inhibition of Ehrlich ascites carcinoma by Manilkara zapota L. stem bark in swiss albino mice. Asian Pac J Sauras Trop Biomed 2011;1:448-51.

12. Chanda SV, Nagani KV. Antioxidant capacity of Manilkara zapota L. leaves extracts evaluated by four in vitro methods. Nat Sci 2010;8:260-66.
13. Nair R, Chanda S. Antimicrobial activity of Terminalia catappa, Manilkara zapota and Piper betel leaf extract. Indian J Pharm Sci 2008;70:390-3.

14. Kaneria M, Baravalia Y, Vaghasiya Y, Chanda S. Determination of antibacterial and antioxidant potential of some medicinal plants from Saurashtra region, India. Indian J Pharm Sci 2009;71:406-12.

15. Sudarshan Singh, Sunil B. Bothara Manilkara zapota (Linn.) seeds: a potential source of natural gum. ISRN Pharm 2014;110. http://dx.doi.org/10.1155/2014/647174

16. Rao PS, Srivastava HC. Tamarind. In: Industrial Gums. 2nd edn. Whistler RL (ed). Academic Press: New York; 1973. p. 369-411.

17. Parodi B, Russo E, Caviglioli G, Cafaggi S, Bignardi G. Development and characterization of a buccoadhesive dosage form of oxycodone hydrochloride. Drug Dev Ind Pharm 1996;22:445-50.

18. Kshirsagar R, Vikas J, Wattamwar S. Effect of different viscosity grade HPMC polymers on gastro retentive drug delivery of metformin Hcl. Int J Appl Pharm 2009;1:44-50.

19. Kashappa Goud, Desai H, Pramod Kumar TM. Preparation and evaluation of a Novel Buccal Adhesive System. AAPS PharmSciTech 2004;5:35.

20. Bagul U, Gujar K, Dhat S, Aphale S, Bhavsar M. In vitro study of mucoadhesive strength of polymers for mucoadhesive drug delivery systems. Int J Curr Pharm Res 2009;1:42-6.

21. Patil P, Kulkarni SV, Rao BS, Ammanage A, Surpur C. Formulation and in vitro evaluation of mucoadhesive tablets of ofloxacin using natural gums. Int J Curr Pharm Res 2011;3:93-8.

22. Gupta S, Dev A. Formulation and characterization of mucoadhesive matrix tablet of nizatidine. Asian J Pharm Clin Res 2018;11:277-83.

23. Hadjiioannou TP, Christian GD, Koupparis MA. Quantitative calculations in pharmaceutical practice and research. New York, NY: VCH Publishers Inc; 1993. p. 345-8.

24. Higuchi T. Mechanism of sustained action medication. Theoretical analysis of the rate of release of solid drugs dispersed in solid matrices. J Pharm Sci 1963;52:1145-9.

25. Bourne DW. Pharmacokinetics. In: Modern Pharmaceutics. 4th edn. Banker GS, Rhodes CT. eds. New York, NY: Marcel Dekker Inc; 2002. p. 67-92.

26. Korsmeyer RW, Gurny R, Doelker E, Buri P, Peppas NA. Mechanisms of solute release from porous hydrophilic polymers. Int J Pharm 1983;15:25-36.

27. Ilango R, Kavimani S, Mullaicharam AR, Jayakar B. In vitro studies on buccal strips of glibenclamide using chitosan. Indian J Pharm Sci 1997;59:232-5.

28. Saraswathi B, Balaji A, Umashankar M. Polymers in mucoadhesive drug delivery system-latest updates. Int J Pharm Pharm Sci 2013;5:423-30.

29. Park H, Robinson JR. Mechanisms of mucoadhesion of poly (acrylic acid) hydrogels. Pharm Res 1987;4:457-64.

30. Peppas NA. Analysis of fickian and non-fickian drug release from polymers. Pharm Acta Helv 1985;60:110-1.

31. Kumar BP, Kavitha P, Devi KJ. Formulation design and evaluation of mucoadhesive buccal tablets of nitroglycerin. Int J Pharm Pharm Sci 2014;6:251-9.

32. Sood A, Panchagnula R. Drug release evaluation of diltiazem CR preparations. Int J Pharm 1998;175:95-107. 